\title{
My body, not my choice: Against legalised abortion
}

\author{
The Journal of Medical Ethics
}

PENULTIMATE DRAFT

\begin{abstract}
It's often assumed that if the fetus is a person, then abortion should be illegal. Judith Thomson laid the groundwork to challenge this assumption, and David Boonin has recently argued that it is false: he argues that abortion should be legal even if the fetus is a person. In this article, I explain both Thomson's and Boonin's reason for thinking that abortion should be legal even if the fetus is a person. After this, I show that Thomson's and Boonin's argument for legalized abortion fail; they have not given us good reason for thinking abortion should be legal. Finally, I argue that_-if we play Boonin's game_-abortion should be illegal.
\end{abstract}

\section{Introduction}

It's often assumed that if the fetus is a person, then abortion should be illegal. Judith Thomson [1] laid the groundwork to challenge this assumption, and David Boonin [2] has recently argued that it is false: he argues that abortion should be legal even if the fetus is a person. In this article, I explain both Thomson's and Boonin's reason for thinking that abortion should be legal even if the fetus is a person. After this, I show that Thomson's and Boonin's argument for legalized abortion fail; they have not given us good reason for thinking abortion should be legal. ${ }^{1}$ Finally, I argue that —if we play Boonin's game_-abortion should be illegal.

\section{Boonin's Argument for Legalized Abortion}

When discussing the ethics and politics of abortion, whether the fetus is a person is usually central (e.g. $[3,4]){ }^{2}$ However, Thomson [1] long ago challenged this view. She argued that abortion is permissible even if the fetus is a person. To do so, she asks us to consider a case in which you are non-consensually taken to a hospital and hooked up to a famous violinist. The violinist, if he is to survive, needs to filter his blood through your body. After nine months, he will be fine and you can unplug yourself and go on your way. If you unplug yourself prior to this, however, he will die. Is it permissible to unplug yourself? Thomson thinks the answer is "Yes." And this, she thinks, shows that abortion is permissible even if the fetus is a person. While the majority of her article focuses on the ethics of abortion, it should be clear to the reader that she also aims to show that abortion should be legal if the fetus is a person; she would no doubt reject the view that the state is right to coerce you into staying plugged into the violinist, and for the same reason she thinks you can unplug yourself from the violinist: no one, not even the state, can demand that you perform such a burdensome task against your will. While Thomson's case for

\footnotetext{
${ }^{1}$ Most of this article addresses Boonin's argument, since it is more developed and recent than Thomson's.

${ }^{2}$ Though, see e.g. $[5,6,7]$ for arguments about abortion that do not concern the moral status of the fetus.
} 
the legality of abortion (even given fetal personhood) is underdeveloped, ${ }^{3}$ Boonin [2] has provided a rigorous defense of this thesis. It is to his argument I now turn.

A legal case, McFall vs. Shimp, undergirds Boonin's argument. Here are the relevant details: in 1978, Robert McFall was diagnosed with a disease that required him to secure a bone marrow transplant quickly. Many people were tested to see if their bone marrow was compatible with McFall's. Only one test came back promising - that of his cousin David Shimp. Before a test to confirm the compatibility of Shimp's bone marrow with McFall's was able to be conducted, Shimp changed his mind: he was no longer willing to give McFall his bone marrow. McFall then sued Shimp in an attempt to get the state to coerce Shimp into giving him (McFall) bone marrow. The judge, however, dismissed the case: Shimp was not coerced into giving McFall his bone marrow. 15 days later, McFall died. Boonin describes the conclusion of the case as follows: the judge's "basic point was simple: it would be wrong for the state to force Shimp to give McFall the bone marrow he needed." [2]

Boonin (plausibly) assumes readers will agree with the judge (and him) that it would be wrong for the state to coerce Shimp into giving McFall his bone marrow. And the reason the state cannot coerce Shimp to give his bone marrow to McFall, says Boonin, is because McFall does not have a right to Shimp's bone marrow. If McFall did, then the state could (and presumably, should) coerce Shimp into giving it to him. So, he says, those who agree with the judge (and him) about the state not being able to coerce Shimp into giving McFall his bone marrow are committed to the view that McFall does not have a right to Shimp's bone marrow. Since McFall was (obviously) a person, ${ }^{4}$ it follows that being a person does not entail that one has a right to another's bone marrow even if you need it to live [2]. The general lesson from this, Boonin argues, is that being a person does not give one a right to use another's body even if it is required to survive. Thus, the state has no right to coerce person $A$ into letting another person $B$ use her body even if $B$ will die without the use of $A$ 's body. This, however, has implications for one's view on what the legal status of abortion should be. Here's why. Assume the fetus is a person. Clearly, the (early) fetus requires the use of its mother's body to survive. However, per Boonin's argument (supported by McFall vs. Shimp), this does not entail that the fetus has a right to the use of its mother's body. If it did, argues Boonin, then McFall would have had a right to Shimp's body. But he did not. And this means that the state should not coerce the mother into providing the use of her body to her fetus. Therefore, the state should not coerce mothers into carrying their fetuses to term, and this is true even if the fetus is a person. And this is true for all types of abortion. In his words, if you agree with the judge in the case of Shimp and McFall, then you should agree that

it should be legal for a woman to have an abortion if her pregnancy is the result of rape, it should be legal for a woman to have an abortion if her pregnancy is the result of contraceptive failure, and it should be legal for a woman to have an abortion if her pregnancy is the result of freely choosing to engage in unprotected sex. [2]

\footnotetext{
${ }^{3}$ See e.g. [8] for a recent challenge to Thomson.

${ }^{4}$ While Boonin refers both to "persons" and those with a "right to life," I will simply take a person to be a thing that has a right to life. Nothing hinges on this point.
} 
In summary, Boonin's argument goes something like this:

(1) Being a person does not give one the right to use another person's body, even if it is needed for survival. (per Mcfall vs. Shimp)

(2) Therefore, even if the fetus is a person, it does not have the right to use its mother's body, even if it is needed for survival.

(3) The state should only coerce $A$ into letting $B$ use her body if $B$ has a right to A's body.

(4) Therefore, the state should not coerce women into not having abortions, even if fetuses are persons.

Boonin defends his argument against a plethora of objections, such as the claim that there are significant differences between the McFall vs. Shimp case and pregnancy. I will not discuss the merits or demerits of his replies to those objections here. Instead, I will undermine his argument by showing that (2) does not follow from (1). In doing so, I try to beat Boonin by playing his own game: I will show that there are cases in which person $B$ does have a right to use another person $A$ 's body in order to survive, and that the state is right to coerce $A$ into letting $B$ use her body. ${ }^{5}$ The upshot of this is that (2) does not follow from (1): even if being a person does not give one person (fetus or otherwise) the right to use another's body, there may be other properties (or conjunctions of properties) that give one person (fetus or otherwise) the right to another's body. My strategy here is not to say what the property (or conjunction of properties) is. ${ }^{6}$ Instead, I will just show that there are clear-cut cases in which one person does have a right to another's body. This is sufficient to show that (2) does not follow from (1) (since the fetus may have other properties (besides personhood) that grant it a right to its mother's body) and hence sufficient to undermine his argument. In other words, while Boonin has (arguably) shown that being a person does not in itself grant someone a right to use another person's body, this does not settle matters, for there are cases in which some persons do have a right to another's body. And hence Boonin's argument fails.

\section{Why Boonin's Argument Fails}

Boonin's argument (obviously) hinges on the thesis that (extraordinary cases aside) the state should not coerce another person to use their body to save another person. ${ }^{7}$ In this section, I will show that there is a clear case in which the state should coerce one into using his or her body to save the life another person. By Boonin's reasoning, this shows that there are clear cases in which one person has a right to the use of another person's body. And this means that there are both cases in which we do have rights to others' bodies and cases in which we do not, which in turn shows that being a person does not guarantee that no one has a right to use your body for survival, thereby rendering the inference from (1) to (2) invalid.

\footnotetext{
${ }^{5}$ Boonin [2] thinks that this strategy is sufficient to undermine his argument, though, he is skeptical about finding such a case. I will (hopefully) show below that his skepticism is unwarranted.

${ }^{6}$ This is because I do not know what the property (or properties) are.

${ }^{7}$ Here, I understand $X$ to coerce $Y$ to $R$ just in case $X$ will harm (broadly construed) $Y$ if $Y$ does not $R$. E.g. the U.S. coerces those with cars to purchase license tabs - if one is caught driving without (or with expired) tabs, she will be subject to a fine.
} 
Let's start with a warm up case:

CASE 1: It should be (and is) generally illegal for a mother to starve her infant when there is food available.

CASE 1, I take it, is not controversial. In fact, we see examples like this play out all the time. For example, in 2017, a young mother named Angel Poole was arrested for the death of her two month old son, whom she starved. Her son was born weighing around 7 pounds and died weighing around 5 pounds. ${ }^{8}$ That a mother can be arrested for not feeding her infant ${ }^{9}$ means that the state coerces unwilling mothers into feeding their infants: ${ }^{10}$ if she does not, she is under threat of being imprisoned for a long period of time. ${ }^{11}$ This means, by Boonin's reasoning, that an infant has a right to use its mother's food. Of course, this does not threaten Boonin's argument, since CASE 1 does not describe a scenario in which the state should (or does) coerce one into using her body to save the life of another person: CASE 1 does not show that an infant has a right to the use of its mother's body, since the food in question might be baby formula.

\section{Consider a second case:}

CASE 2: It should be generally illegal for a mother to starve her infant when there is food available and the only food available is her breastmilk. ${ }^{12}$

I suspect that CASE 2 is - like CASE 1 - not terribly controversial. ${ }^{13}$ However, by Boonin's reasoning, it follows from CASE 2 that an infant has the right (in certain circumstances-namely, when no other food source is available) to the use of her mother's body or to be transferred to a party willing to care for her-she has the right to her mother's breastmilk when no other food is available or to be transferred to a willing provider. In cases in which the infant cannot be transferred to a willing provider (such as the cases discussed below), the infant will have a right to her mother's breastmilk and so a right to her mother's body. And this shows that being a person does not necessarily entail that no one ever has the right to use your body; some persons in some circumstances have the right to others' bodies. Therefore, (2) of Boonin's argument does not follow from premise (1), and Boonin's argument fails. Put differently, since in both McFall vs. Shimp and CASE 2, those involved are persons, we can see that being a person is insufficient to give one a right to another's body. But CASE 2 shows that this - the insufficiency of personhood to grant a right to another's body - does not entail that a fetus does not have a right

\footnotetext{
${ }^{8}$ You can find the details of this case here: https://ktvo.com/news/local/se-iowa-mother-convicted-of-starving-son-to-death-gets-10-years

${ }^{9}$ I ignore fathers for the sake of simplicity. But, obviously, fathers can be, should be, and are arrested for starving their infants as well.

${ }^{10}$ By "unwilling mother," I just mean a mother that does not want to take care of her infant.

${ }^{11}$ More exactly, she must give up the infant or feed it. I suppose here that she has not given it up and also does not want to feed it.

${ }^{12} \mathrm{I}$ intend this to mean that the mother would have to breastfeed her infant for her infant to get the breastmilk, not just that she has a bottle of breastmilk available.

${ }^{13}$ Of course, this is an empirical question to which no survey has (to my knowledge) been conducted. For whatever it is worth, anecdotally, the vast majority of persons that I have asked about CASE 2 have agreed with it.
} 
to its mother's body. Instead, what Boonin has shown is merely that if a fetus has a right to its mother's body, being a person is not what gives it that right. And hence premise (1) (and McFall vs. Shimp) does not entail (2). In other words, even if we grant Boonin's view about personhood being insufficient to generate a right to the use of another's body, it does not follow that a fetus does not have a right to its mother's body, since there may be other properties (or conjunctions of properties) that grant the fetus this right (as CASE 2 illustrates); (2) does not follow from premise (1), since there are other properties that can ground rights to others' bodies. And hence Boonin's argument fails - or, at least, those who accept CASE 2 should reject it. And if I am right about the popularity of CASE 2, most ought to reject Boonin's argument for legalized abortion.

Now, perhaps Boonin would object that CASE 2 does not really challenge his argument, since in typical cases the mother has voluntarily taken on the responsibility of caring for her infant by not giving her (the infant) up for adoption. That is, typically the mother has voluntarily taken responsibility to care for the infant, and this explains why she is obligated to feed and care for her. However, in the case of an unwanted pregnancy, the woman has not voluntarily taken the responsibility to care for the fetus. And hence CASE 2 does not threaten Boonin's argument. I think there is some reason to doubt this objection, but I will not challenge it here. ${ }^{14}$ To circumvent this objection, we need only to slightly modify CASE 2 to

CASE 2*: It should be generally illegal for a mother to starve her infant when there is food available and the only food available is her breastmilk, even if the mother does not want the infant and has not voluntarily taken responsibility for her. ${ }^{15}$

From CASE 2* we can see that an infant has the right to its mother's breastmilk or to be transferred to a willing provider - even if the mother does not want the infant and has not voluntarily taken responsibility for her. So, in cases in which a transfer is not possible, the infant will have a right to use her mother's body-even when her mother has not voluntarily taken responsibility for her.

Now, CASE 2* is rather abstract, so let's consider a particular application of it.

CABIN: Sally is 9 months pregnant. Unfortunately — as occasionally happens — she doesn't know that she's pregnant. One day, while out hiking, a snowstorm unexpectedly hits, and she is forced to take shelter in a cabin. To make matters worse, she goes into labor while stuck in the cabin. The birth goes well, and her baby is healthy. Sally is stuck in her cabin for 7 days before she is finally dug out. Rescuers find her alive and well, but her infant is dead due to starvation-Sally did not feed her infant, despite having ample food for herself, and producing ample breastmilk (there was no baby formula available in the cabin).

\footnotetext{
${ }^{14}$ For example, some argue that mothers are responsible for the care of their fetuses (in typical cases) in which the pregnancy is unwanted. See e.g. [9, 10].

${ }^{15}$ The qualification "only" here entails that the infant is not able to be transferred to someone else to be fed.
} 
Now, if CASE 2* is right, then in CABIN, it should be illegal for Sally to starve her infant; the state would be right to coerce her into feeding her infant. ${ }^{16}$ As with CASE 2, I suspect that this view is widely shared. However, in CABIN, Sally has not voluntarily undertaken responsibility to care for her infant. Instead, she just happens to be the only person able to care for her infant (much like pregnant women are the only people able to care for fetuses). Since the government can coerce her into using her body to care for her infant (in this case, by breastfeeding her infant), ${ }^{17}$ this means that the government can coerce people into letting other people use their bodies even when they have not voluntarily undertaken responsibility to care for them. But if this is the case, then the above objection is circumvented, and Boonin's inference from (1) to (2) remains undermined.

\section{In Defense of CASE 2*}

Perhaps one is dubious about CASE $2 *$. To provide motivation for it, I will illustrate an (apparently) undesirable consequence of rejecting it. For those who (like me) find this consequence to be implausible, there is reason to accept CASE 2* (aside from its initial plausibility) and hence to reject Boonin's argument. Consider the following variation of CABIN:

CABIN*: Same details as CABIN, with one exception: Sally has ample baby formula available and does not use any of it to feed her infant. Instead, she lets her (the infant) starve to death.

If one rejects CASE $2 *$, then she should hold that Sally should not be coerced into feeding her infant in CABIN. However, CABIN* only requires Sally to feed her infant with baby formula-she does not have to use her body directly to feed her infant - and this means that one's reason for thinking the state should not coerce Sally into feeding her infant in CABIN dissolves: the only reason for thinking Sally does not (legally) need to feed her infant in CABIN is the fact that it requires the use of her body. But in CABIN*, no such use is required, and hence that Sally's actions should be illegal in CABIN* is (extra) uncontroversial. Thus, those that reject CASE $2^{*}$ will hold that Sally's actions in CABIN should be legal while her actions in CABIN* should be illegal. This, however, is a wild position to take. In both CABIN and CABIN*, Sally is able to feed her infant. The only difference is that in CABIN, she must breastfeed her infant. This difference is too trivial to explain the (purported) difference in the ideal legality of Sally's actions in CABIN and CABIN*-are we to take seriously the suggestion that the state has the right to coerce one into formula feeding her child to avoid starvation but not the right to coerce one into breastfeeding her child to avoid starvation? Hardly. Or, at the very least, Boonin has some explaining to do.

To reiterate: in CASE 2, CASE 2*, CABIN, and CABIN*, my purpose is not to say why a mother starving her infant is immoral, nor is it to show why the state can coerce mothers into (in certain circumstances) breastfeeding their infants. My purpose is simply to show cases in which

\footnotetext{
${ }^{16}$ Of course, in this case, the infant is dead, so the state cannot coerce her into feeding her infant after she is taken from the cabin. My point is the state would be right in enacting a law that generally punished those who let their infants starve when there was food available. If there were such a law, the state would be coercing Sally into feeding her infant.

${ }^{17}$ How might the government coerce Sally? One way would be to have laws that dictate that she be fined or imprisoned if she were to starve her infant in such a case.
} 
the state ought to coerce one set of persons (mothers) to use their bodies to keep other persons (infants) alive. And by Boonin's reasoning, this shows that in certain circumstances infants have a right to their mothers' breastmilk. Again, I do not claim to have shown that it is the infant's being a person that gives it a right to its mother's breastmilk ${ }^{18}$ - maybe it is something else. There is no need to settle this matter here. The fact that there are cases in which one person has a right to another's body is sufficient to show that Boonin's argument for the legalized abortion fails.

\section{Abortion Should Be Illegal if the Fetus is a Person}

Above, I argued that Boonin's argument for the legality of abortion (given fetal personhood $)^{19}$ fails. I will now argue, more ambitiously, that CASE $2 *$ gives us good reason to think that abortion should be illegal if the fetus is a person. The above discussion showed that there are some cases in which the state should coerce a person $A$ to let another person $B$ use her body (CASE 2*, and CABIN), and there are some cases in which the state should not coerce $A$ into letting $B$ use her body (McFall vs. Shimp). When considering the legality of abortion, the issue, then, is whether pregnancy/abortion is more like McFall vs. Shimp or more like CASE 2*. If it is more like CASE $2^{*}$, then - if we are playing Boonin's game-we have good reason to think that abortion should be illegal, and if it more like McFall vs. Shimp, then we have good reason to think that it should be legal.

It seems clear that pregnancy/abortion is more like CASE 2* than it is McFall vs. Shimp, even if you tweak the details in the McFall vs. Shimp case. This is for the simple fact that a newborn infant is as close to an in utero fetus as one can be without actually being an in utero fetus. So if, per CASE $2^{*}$, it should be generally illegal for an unwilling mother to starve her newborn infant, then it seems that should guide our thinking about the legality of abortion, not McFall vs. Shimp. Even by tweaking the McFall vs. Shimp case, it is dubious to suppose that it will be more similar to pregnancy/abortion than a newborn infant. In other words, CASE $2 *$ seems to be as close as you can get to pregnancy/abortion without actually being the same as it (i.e. pregnancy/abortion). And thus, no matter how you change the McFall vs. Shimp case to make it more analogous to pregnancy/abortion, it will never be closer than CASE $2 *{ }^{20}$ Thus, if we follow Boonin in thinking that examples like this should guide how we think about the legality of abortion, this gives us good reason to think that if CASE $2 *$ is true, then the state should coerce women into not having an abortion: if the state should coerce mothers into feeding their infants, it should (very likely) also coerce pregnant women into continuing to sustain their fetuses. And so abortion should be illegal if the fetus is a person.

\footnotetext{
${ }^{18}$ Indeed, if one accepts Boonin's view that McFall does not have the right to use Shimp's body, then being a person is not sufficient for having a right to use another's body. So, in the case of abortion and infant starvation, some other property (or conjunction of properties) is what gives the fetus the right to its mother's body.

${ }^{19}$ Hereafter, I will omit the qualification "given fetal personhood" for the sake of readability. However, it should be clear that my discussion is following Boonin and Thomson and assuming fetal personhood.

${ }^{20}$ Indeed, a referee points out that if McFall vs. Shimp is to be made analogous to pregnancy/abortion, then, first, we would need to assume that Shimp had been giving McFall bone marrow (but not given him a sufficient amount). And, second, we would need to assume that to stop giving bone marrow to McFall, Shimp would have to actively kill him in some way (for a defense of abortion as killing, see [4]). In that case, it is not clear that McFall should not be coerced into giving more bone marrow to Shimp, and therefore not clear whether McFall vs. Shimp supports Boonin's position.
} 
(Again, even if this argument is rejected - even if there is a way to show that McFall vs. Shimp is closer to pregnancy/abortion than CASE $2 *$ - it nevertheless remains true that Boonin's argument for the legality of abortion fails.)

\section{Objection: Immoral Yet Legal?}

Of course, a natural objection here is to say that even if a mother letting her infant starve when the only food available is breastmilk is immoral, it should nevertheless remain legal for her to do so. This is similar to Boonin's claim that even if it is immoral for Shimp to refuse to donate his bone marrow to McFall, that it nevertheless should remain legal for him to refuse, and to Thomson's claim that even if it is immoral for one to unplug herself from the violinist, that it nevertheless should be legal for her to do so. Of course, it's no doubt true that actions should not be criminalized because they are immoral (it should not be illegal to lie to one's friends, for example). ${ }^{21}$ So, how are we do decide whether CASE $2 *$ is true? How can we tell whether it should be illegal for one to let her infant starve when she is able to provide breast milk and the infant cannot be transferred to a willing provider? The clearest way to do so is to follow Michael Huemer's method [11], and consider what actions are permissible for you or me to coerce someone into performing. If an action is not permissible for you or me to coerce someone into doing, then (argues Huemer), it's not permissible for the government to coerce someone into performing that action. For example, suppose that my neighborhood is experiencing a rise in crime. My neighbor, Sam, decides that enough is enough: he is going to get together with some of his friends and patrol the neighborhood in an attempt to catch these criminals. Every night they go out on patrol. When they find someone committing a crime, they subdue the criminal, bring them to Sam's basement, and lock them down there for a period of time to make amends for their crime (and to deter future criminals). Of course, it isn't free for Sam and his friends to do this: it takes time and money (they have to feed and clothe those locked up in Sam's basement, among other things). As such, Sam and his friends start going door to door in the neighborhood to extract funds for their project. At each house, Sam asks the resident if they've noticed a drop in crime recently, which, of course, they have. He then reveals that he and his friends are the reason that this has happened, and informs the resident that it costs money for him to do this. Then he demands $\$ 100$ monthly from the resident to fund his activities. If the resident refuses, then Sam informs him that he (Sam) will be forced to lock up the resident in his basement. Since Sam provides services for the community, is it permissible for Sam to coerce his neighbors into giving him money? Clearly, the answer is No. But if it's impermissible for Sam to do this, then it's impermissible for the government to act as such. (This is all, of course, oversimplified. For the whole story, see [11].)

So, where does this leave us with respect to CASE $2 *$ and CABIN? What we need to consider, here, is whether it would be permissible for you or me to coerce a mother into feeding her infant when there was no other food available and a transfer is not possible. So, suppose you found yourself snowed in a cabin with a woman and her infant. There was ample adult food available, but no baby formula - the only way to feed the infant is by way of breastfeeding. It seems clear that not only is it permissible for you to coerce the mother into feeding her infant,

\footnotetext{
${ }^{21}$ It is equally true that not all ethically permissible actions should be legal (e.g. slightly exceeding the speed limit on a road should not be legal).
} 
but that you should do so. Following Huemer's method, this means that the government can coerce mothers into breastfeeding their children when there is no other food available, and so (at least) typical objections to this position will not apply. So, it is permissible for the government to coerce women into feeding their infants (when a transfer is not possible). But is that the sort of thing the government should do? It seems so: the government would be right to coerce a mother into breastfeeding her infant when there is no alternative food source and a transfer isn't possible. Indeed, if the government should do anything, it should help ensure the survival of extremely vulnerable community members. ${ }^{22}$ (How would the government coercion work here? Perhaps through enacting general laws that fine people for not feeding their children when it is feasible to do so.)

Of course, judgments will differ here. Some will share my view on this matter and will reject the objection addressed in this section. Others who don't share this judgment will not reject the objection — or, at least, they will not necessarily reject it. However, I suspect that the view articulated in this section is, if not widely held, at least substantially held - anecdotally, people tend to favor the government providing basic aid for those in danger of perishing, even if the aid is costly ${ }^{23}$ - meaning that many will have reason to reject the objection considered in this section. ${ }^{24}$

Acknowledgements: For comments on this article, thanks to Kyle Blanchette, Brian Eckley, Sarah DeWitt Lucas, and Sami Seybold. And thanks especially to G.L.G.-Colin Patrick Mitchell—for particularly insightful comments.

\section{References}

1. Thomson, Judith. (1971). "A defense of abortion", Philosophy and Public Affairs, 1: 47-66.

2. Boonin, David. (2019). Beyond Roe: Why Abortion Should be Legal-Even if the Fetus is a Person. Oxford University Press.

3. Kaczor, Christopher. (2011). The Ethics of Abortion: Women's Rights, Human Life, and the Question of Justice. Routledge.

4. Greasley, Kate. (2017). Arguments About Abortion: Personhood, Morality, and Law. Oxford University Press.

5. Hendricks Perry. (2019). "Even if the fetus is not a person, abortion is immoral: The impairment argument." Bioethics 33: 245-253.

6. Hershenov, D. (2018). Health, Moral Status, and a Minimal Speciesism. Res Philosophica 95(4): 693-718

\footnotetext{
${ }^{22}$ Of course, this does not mean that anything goes - there will be heavy restrictions on what the government can/should do here.

${ }^{23}$ Think of the popularity (in certain parts of the world) of government provided healthcare.

${ }^{24}$ It is worth noting that there are some legal cases that offer support for CASE $2 *$. For example, Francis Beckwith considers a case in American tort law in [12], pages 196-197, which arguably supports the conclusion of this section. I do not consider a such rulings in this piece partly because there are bound to be cases that support both sides and partly because I think we can see, independent of prior rulings, that CASE $2 *$ is right.
} 
7. Marquis, Don. (1989). "Why Abortion is Immoral.” The Journal of Philosophy LXXXVI: 183-202.

8. Schouten, Gina. (2017). "Fetuses, Orphans, and a Famous Violinist" Social Theory and Practice 43 (3): 637-665.

9. Bernstein, C'zar and Paul Manata. (2019). "Moral Responsibility and the Wrongness of Abortion" Journal of Medicine and Philosophy (2): 243-262.

10. Lang, Gerald. (2008). "Nudging the Responsibility Objection" Journal of Applied Philosophy (1)

11. Huemer, Michael. (2014). The Problem of Political Authority: The Right to Coerce and the Duty to Obey. Palgrave-Macmillan.

12. Beckwith, Frances. Defending Life: A Moral and Legal Case Against Abortion Choice. Cambridge University Press. 